\title{
Reaction Mechanism of Embedding Oxidizing Small Molecules in Energetic Materials to Improve the Energy by Reactive Molecular Dynamics Simulations
}

Yiwen Xiao, Lang Chen", Deshen Geng, Kun Yang, Jianying Lu, Junying Wu and Binshuo Yu

State Key Laboratory of Explosion Science and Technology, Beijing Institute of Technology, Beijing 100081, China

\section{Supporting Information}

\section{Table of Contents}

S1: Dissociation curves of the hydrogen bonding between CL-20 and $\mathrm{H}_{2} \mathrm{O}_{2}$.

S2: Dissociation curves of the (a) $\mathrm{O}-\mathrm{O}$ and (b) $\mathrm{H}-\mathrm{O}$ bonds of $\mathrm{H}_{2} \mathrm{O}_{2}$.

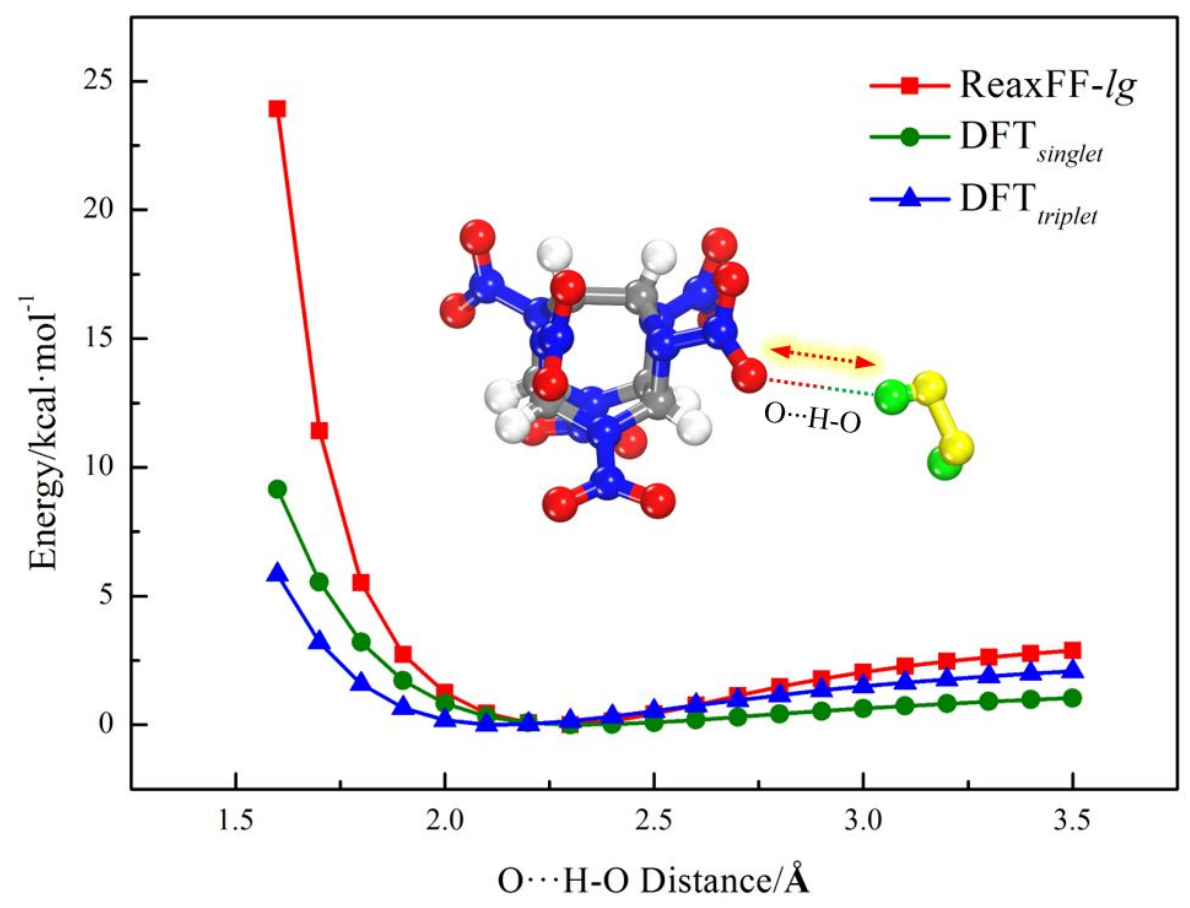

Figure S1 Dissociation curves of the hydrogen bonding between CL-20 and $\mathrm{H}_{2} \mathrm{O}_{2}$.

* Corresponding author: Lang Chen, Tel \& Fax: +86 1068914711. 

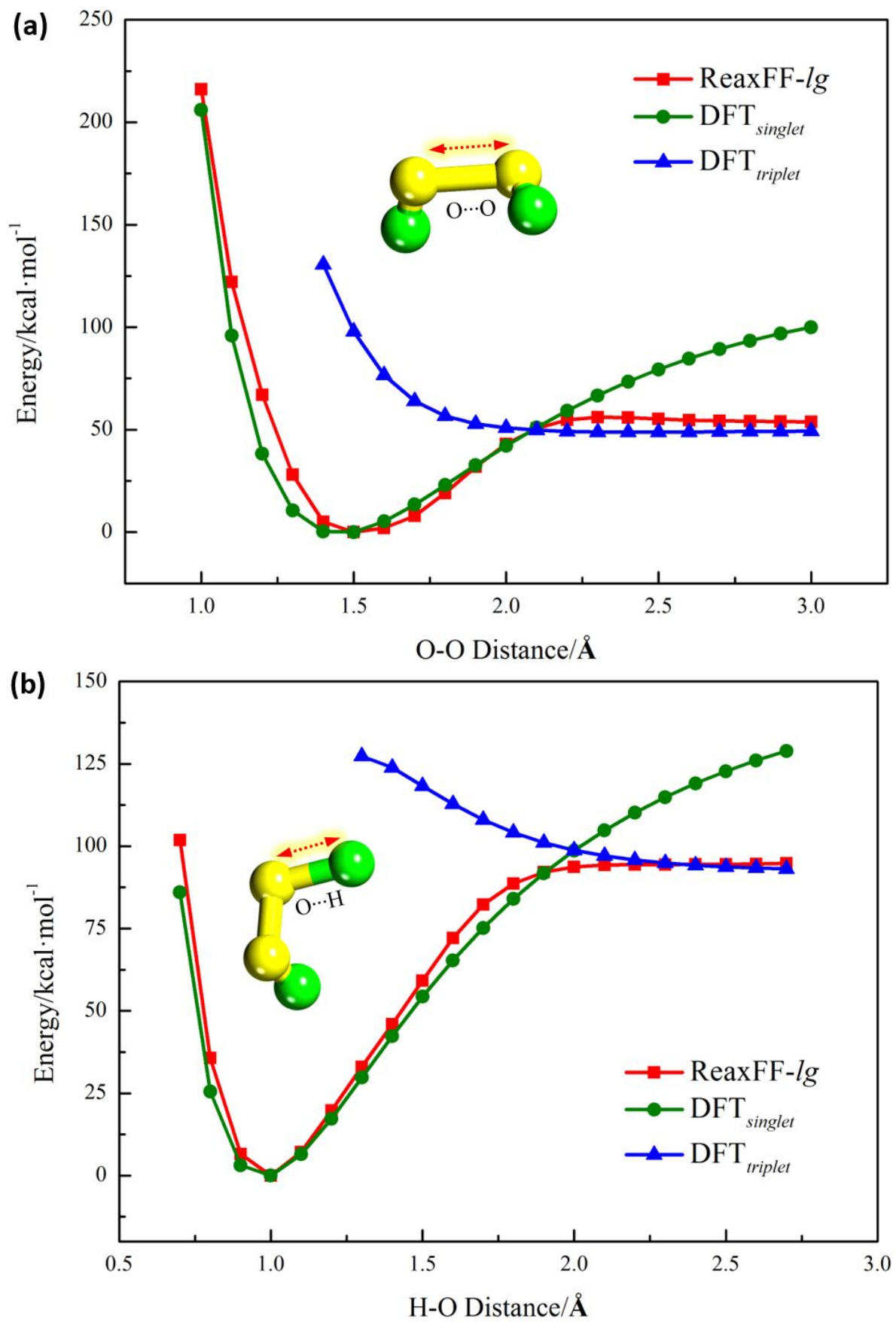

Figure S2 Dissociation curves of the (a) $\mathrm{O}-\mathrm{O}$ and (b) $\mathrm{H}-\mathrm{O}$ bonds of $\mathrm{H}_{2} \mathrm{O}_{2}$. 